\title{
High Grade Highway Asphalt Pavement Maintenance Optimization
}

\section{Evaluation}

\author{
Hongli Zhao ${ }^{1, a}$, Guangyu Zhou ${ }^{2, b}$ and Shengbing $\mathrm{Du}^{3, \mathrm{c}}$ \\ ${ }^{1,2,3}$ Hydraulic engineering department,Shandong water polytechnic, Rizhao, China \\ a34617063@qq.com, ${ }^{b}$ 86508417@qq.com, ${ }^{c}$ 452544226@qq.com
}

Key words: pavement performance; single index; comprehensive evaluation; optimization Abstract: Starting from the existing evaluation system of asphalt pavement, single evaluation index and the comprehensive evaluation index are evaluated respectively. Based on engineering examples, this paper puts forward that the weighted geometric mean generation is to optimize the existing weighted arithmetic mean, practice has proved that the optimized evaluation system is more scientific and more close to the engineering practice.

Highway asphalt pavement is a main type of highway in our country, which plays a very important role in road traffic. By the end of 2015, the highway mileage of China reached 125000 kilometers, which takes up $75 \%$ of asphalt pavement. However, with the development of chemotactic traffic, traffic volume and axle load frequency increases, coupled with a combination of natural factors, the highway asphalt pavement performance presents the downward trend year by year. So, for highway management department, a set of scientific and reasonable index evaluation system is particularly important. This paper analyzed preliminarily.

\section{Asphalt pavement performance evaluation}

In 1962, Garey and Irick pavement performance is defined as "the evolution of the pavement service ability" ${ }^{[1]}{ }^{[2]}$. In 1992, W.D.O.P aterson new road use performance is defined as "the road to road users to provide services" ${ }^{[3][4]}$. The pavement performance evaluation can be divided into the single index evaluation and comprehensive evaluation. Single index evaluation concerns mainly pavement damage condition, ride quality, pavement structure strength and safety performance indicators which consists of the four big indexes to evaluate the road performance of various aspects. The comprehensive evaluation index is the weighting of the single index values. So the comprehensive evaluation must be carried out. The first single evaluation and individual evaluation index is the basis of the comprehensive evaluation index.

\section{Single evaluation index}

\section{Pavement damage condition (PCI)}

Pavement damage condition is a complex phenomenon, in our country's current "technical specification for highway asphalt pavement maintenance (JTJ 073.2-2001), the surface of damaged road will be conditioned by pavement condition index (PCI).Because the pavement damage is a result of the combined action of various factors, from the pavement type, extent of damage and damage the scope of the three aspects: we can establish a PCI function to evaluate, According to the type (1), (2) it is calculated as follows: 


$$
\begin{array}{r}
P C I=100-a_{0} D R^{a_{1}} \\
D R=100 \times \frac{\sum_{i=1}^{i_{0}} W_{i} A_{i}}{A}
\end{array}
$$

$D R$ — Pavement damage rate for the sum of all kinds of damage or damage to the area and area percentage of pavement survey $(\%)$;

$A_{i}$ - The first class I road damage area, $\mathrm{m}^{2}$;

$A$ - Investigation of road area, the product of length and the effective width of the road, $m^{2}$;

$W_{i}$ - The weight of the $\mathrm{i}$ class pavement, the asphalt pavement according to the values in table 1 ;

$a_{0}$ _ using 15.00 for Asphalt pavement;

$a_{1}$ _using 0.412 for Asphalt pavement;

$i$ _Considering damage (light, medium, heavy) of the i type pavement damage;

$i_{0}$ - Contain damage (light, medium, heavy) total damage type, using 21 for Asphalt pavement.

According to the type (1) and (2), we can calculate the PCI value, the greater of the value the better of PCI status of asphalt pavement. According to the size of the PCI generation numerical, the conditions of asphalt pavement are divided into five grades: the excellent, the good, the average, the poor and the worse. The specific classifications are shown in Table 2. 
Table 1 Asphalt pavement damage type and weight

\begin{tabular}{|c|c|c|c|c|}
\hline Type & $\begin{array}{l}\text { Damage to the na- } \\
\text { me }\end{array}$ & $\begin{array}{l}\text { Extent of the da-m } \\
\text { age }\end{array}$ & weight & measuring unit \\
\hline $\begin{array}{l}1 \\
2 \\
3\end{array}$ & crack & $\begin{array}{l}\text { light } \\
\text { medium } \\
\text { heavy }\end{array}$ & $\begin{array}{l}0.6 \\
0.8 \\
1.0\end{array}$ & $m^{2}$ \\
\hline $\begin{array}{l}4 \\
5\end{array}$ & The massive crack-s & $\begin{array}{l}\text { light } \\
\text { heavy }\end{array}$ & $\begin{array}{l}0.6 \\
0.8\end{array}$ & $m^{2}$ \\
\hline $\begin{array}{l}6 \\
7\end{array}$ & Longitudinal crack-s & $\begin{array}{l}\text { light } \\
\text { heavy }\end{array}$ & $\begin{array}{l}0.6 \\
1.0\end{array}$ & $\begin{array}{l}\text { m } \\
\text { (Influence width: } \\
0.2 \mathrm{~m} \text { ) }\end{array}$ \\
\hline $\begin{array}{l}8 \\
9\end{array}$ & Transverse cracks & $\begin{array}{l}\text { light } \\
\text { heavy }\end{array}$ & $\begin{array}{l}0.6 \\
1.0\end{array}$ & $\begin{array}{l}\text { m } \\
\text { (Influence width: } \\
0.2 \mathrm{~m} \text { ) }\end{array}$ \\
\hline $\begin{array}{l}10 \\
11\end{array}$ & Pit slot & $\begin{array}{l}\text { light } \\
\text { heavy }\end{array}$ & $\begin{array}{l}0.8 \\
1.0\end{array}$ & $m^{2}$ \\
\hline $\begin{array}{l}12 \\
13\end{array}$ & loose & $\begin{array}{l}\text { light } \\
\text { heavy }\end{array}$ & $\begin{array}{l}0.6 \\
1.0\end{array}$ & $m^{2}$ \\
\hline $\begin{array}{l}14 \\
15\end{array}$ & subsidence & $\begin{array}{l}\text { light } \\
\text { heavy }\end{array}$ & $\begin{array}{l}0.6 \\
1.0\end{array}$ & $m^{2}$ \\
\hline $\begin{array}{l}16 \\
17\end{array}$ & rut & $\begin{array}{l}\text { light } \\
\text { heavy }\end{array}$ & $\begin{array}{l}0.6 \\
1.0\end{array}$ & $\begin{array}{l}m^{2} \\
\text { (Influence width: } \\
0.2 \mathrm{~m} \text { ) }\end{array}$ \\
\hline $\begin{array}{l}18 \\
19\end{array}$ & $\begin{array}{l}\text { The waves on pac-k } \\
\text { age }\end{array}$ & $\begin{array}{l}\text { light } \\
\text { heavy }\end{array}$ & $\begin{array}{l}0.6 \\
1.0\end{array}$ & $m^{2}$ \\
\hline 20 & flushing & & 0.2 & $m^{2}$ \\
\hline 21 & repair & & 0.1 & $m^{2}$ \\
\hline
\end{tabular}

Table 2 Pavement condition evaluation standard

\begin{tabular}{|l|c|c|c|c|c|}
\hline \multicolumn{1}{|c|}{ level } & A & B & C & D & E \\
indicators & & & & & $<40$ \\
\hline $\begin{array}{l}\text { Pavement condition inde } \\
\text {-x PCI }\end{array}$ & $\geq 85$ & $70 \leq \sim \angle 85$ & $55 \leq \sim \angle 70$ & $40 \leq \sim \angle 55$ & $<40$ \\
\hline
\end{tabular}

\section{Ride quality (RQI) evaluation}

Ride quality index is reflection of the vehicle ride comfort, safety and economy, is one of the important parameters reflecting pavement service ability. Flatness is an important index to evaluate the quality of the surface road, and is directly related to the size of the maintenance of quantities and the durability of pavement. In the Communications Standard Terms of the Ministry, the highway engineering "(JTJ 00287) pavement roughness is defined as: the amount of longitudinal 
road surface concave and convex. International roughness IRI with its own characteristics (IRI is associated with the dynamic response of vehicle vibration, through the $1 / 4$ vehicle model is established with the vehicle performance correlation; IRI directly associated with the road section elevation, ensure that the results with time stability; IRI can pass the most widely used instrument were measured, the result is effective; IRI could be transformed in the world, has the transferability.) become the most widely used international roughness index. The relationship between pavement quality indexRQI international roughness IRI can be calculated by type (3) format as follows:

$$
R Q I=\frac{100}{1+a_{0} e^{a_{1} I R I}}
$$

IRI — The international roughness index, $\mathrm{m} / \mathrm{km}$;

$a_{0}$ _Freeway and first class road is using 0.026 , the other is 0.0185 ;

$a_{1}$ _Freeway and first class road is using 0.65 , the other is 0.58 .

According to the type (3) ROI value, will ride quality standards are divided into five grades: the excellent, the good, the average, the poor and the worse, specific standard is shown inTable 3.

Table 3 The ride quality evaluation standard

\begin{tabular}{|l|c|c|c|c|c|}
\hline level & A & B & C & D & E \\
\hline Rindicators quality RQI & $\geq 8.5$ & $7.0 \leq \sim \angle 8.5$ & $5.5 \leq \sim \angle 7.0$ & $4.0 \leq \sim \angle 5.5$ & $<4.0$ \\
\hline
\end{tabular}

\section{Pavement structure intensity evaluation (PSSI)}

The strength of the pavement structure means the times the traffic road can withstand before the expected damage condition, or the use of the number of year ${ }^{[4]}$, usually evaluated by the available PSSI strength index, and calculated according to type (4), (5) .

$$
\begin{gathered}
P S S I=\frac{100}{1+a_{0} e^{a_{1} S S I}} \\
S S I=\frac{l_{d}}{l_{0}}
\end{gathered}
$$

SSI _ Pavement structure strength coefficient;

$l_{d}$ _Pavement design deflection, $0.01 \mathrm{~mm}$;

$l_{0}$ _The measured deflection, $0.01 \mathrm{~mm}$;

$a_{0}$ _-Model parameters, 15.71 ;

$a_{1}$-Model parameters, -5.19 . 
Among them, the structure strength index of SSI in pavement is determined by the bearing capacity of pavement structure between design deflection and the actual deflection ratio, and can estimate the residual life of pavement structure for highway management to adopt reasonable economic maintenance countermeasures to provide the necessary basis. When $\mathrm{SSI} \geq 1$, pavement structure strength is in a reasonable basis; When the SSI $<1$, the pavement structure intensity or vehicle load is more than the bearing capacity of pavement structure, maintenance management department shall take the necessary measures.Specific division standard is shown in Table 4.

Table 4 Asphalt pavement structural strength standard

\begin{tabular}{|l|c|c|c|c|c|}
\hline evaluation index & $\mathrm{A}$ & $\mathrm{B}$ & $\mathrm{C}$ & $\mathrm{D}$ & $\mathrm{E}$ \\
\hline $\begin{array}{l}\text { Intensity index } \\
\text { SSI }\end{array}$ & $\geq 1.0$ & {$[0.83,1.0)$} & {$[0.66,0.83)$} & {$[0.5,0.66)$} & $<0.5$ \\
\hline
\end{tabular}

\section{Road safety performance evaluation (SRI)}

Anti-sliding ability index is one of the main function of asphalt pavement, it is to ensure that the vehicle in the asphalt pavement, especially on rainy days for the sake of safe driving. Pavement anti-sliding ability evaluation is to measure the performance of asphalt pavement in security. It usually evaluated by the use of SRI anti-sliding performance index, thus calculated according to the type (6), (7).

$$
\begin{gathered}
S R I=\frac{100-S R I_{\text {min }}}{1+a_{0} e^{a_{1} S F C}}+S R I_{\text {min }} \\
S F C=1.98 B P N-34
\end{gathered}
$$

$S F C$ - Lateral force coefficient;

$S R I_{\min }$ - Calibration coefficient, 35.0;

$a_{0}$ - Model parameters, 28.6;

$a_{1}$-Model parameters, -0.105 .

Table 5 Pavement anti-sliding performance evaluation standard

\begin{tabular}{|l|c|c|c|c|c|}
\hline indicators & $\mathrm{A}$ & $\mathrm{B}$ & $\mathrm{C}$ & $\mathrm{D}$ & $\mathrm{E}$ \\
\hline $\begin{array}{l}\text { Set the value } \\
\text { BPN }\end{array}$ & $\geq 42$ & {$\left[\begin{array}{ll}37, & 42\end{array}\right)$} & {$\left[\begin{array}{ll}32, & 37\end{array}\right)$} & {$\left[\begin{array}{ll}27, & 32\end{array}\right)$} & $<27$ \\
\hline $\begin{array}{l}\text { Lateralforce coeffi } \\
\text {-cient SFC }\end{array}$ & $\geq 50$ & {$\left[\begin{array}{ll}40, & 50\end{array}\right)$} & {$\left[\begin{array}{ll}30, & 40\end{array}\right)$} & {$\left[\begin{array}{ll}20, & 30\end{array}\right)$} & $<20$ \\
\hline
\end{tabular}

\section{Comprehensive evaluation index}

Pavement performance has many aspects of properties, which in use process have different decay process, meeting the requirement of different level; this requires conducting one-way evaluation index of pavement performance. And the comprehensive evaluation index can comprehensively reflect the performance of pavements, more comprehensive evaluation of pavement performance is the overall evaluation of the road, it contains the information of components of assessment indexes of pavement.

Comprehensive evaluation index is usually presented buy PQI, and usually uses pavement performance of each sub-index weighted arithmetic mean, as: 


$$
P Q I=W_{P C I} \times P C I^{\prime}+W_{R Q I} \times R Q I^{\prime}+W_{S S I} \times S S I^{\prime}+W_{S R I} \times S R I^{\prime}
$$

$W_{P C I} 、 W_{R Q I} 、 W_{S S I} 、 W_{S R I}$ is respectively corresponding to the weights of indicators and can be obtained through Table 6. According to the calculated values of PQI value (specific evaluation standard are shown in table 7), it can evaluate the overall situation of asphalt pavement, highway management departments can adopt corresponding maintenance countermeasures according to the overall evaluation, implement reasonable maintenance.

Table 6 Asphalt pavement PQI index weights separately

\begin{tabular}{|l|c|c|c|}
\hline road surface type & weight & free、 first class way & $\begin{array}{l}\text { second third fourth class } \\
\text { way }\end{array}$ \\
\hline \multirow{2}{*}{$\begin{array}{l}\text { Asphalt paveme } \\
\text { nt }\end{array}$} & $W_{P C I}$ & 0.35 & 0.60 \\
\cline { 2 - 4 } & $W_{R Q I}$ & 0.40 & 0.40 \\
\cline { 2 - 4 } & $W_{S S I}$ & 0.15 & - \\
\cline { 2 - 4 } & $W_{S R I}$ & 0.10 & - \\
\hline
\end{tabular}

Table 7 PQI evaluation standard of asphalt pavement

\begin{tabular}{|l|c|c|c|c|c|}
\hline \multicolumn{1}{|c|}{ level } & A & B & C & D & E \\
\hline $\begin{array}{l}\text { indicators } \\
\text { Synthetic condition } \\
\text { index PQI }\end{array}$ & $\geq 85$ & $70 \leq \sim \angle 85$ & $55 \leq \sim \angle 70$ & $40 \leq \sim \angle 55$ & $<40$ \\
\hline
\end{tabular}

\section{The comprehensive evaluation index improvement Suggestions}

\section{PQI calculation based on the weighted arithmetic}

There exist two different sections of some freeway asphalt pavement in Shandong, with the aid of related testing instrument and calculated respectively two groups of data for PCI, RQI, SSI, SRI, type (8) is used to calculate the PQI, the results are shown in table 8.

Table 8 Calculation results of two sections of PQI

\begin{tabular}{|l|c|c|c|c|c|}
\hline $\begin{array}{c}\text { parameter } \\
\text { group }\end{array}$ & PCI' $^{\prime}$ & RQI' $^{\prime}$ & SSI' $^{\prime}$ & SRI' $^{\prime}$ & PQI \\
\hline 1 group & 80 & 45 & 78 & 82 & 65.9 \\
\hline 2 group & 68 & 65 & 60 & 71 & 65.9 \\
\hline
\end{tabular}

note: PCI'

According to the data in Table 8, we found that, although there is a big difference between the two groups of data investigation, but we found by calculation, the calculation result is the same: 65.9, the rating is consistent, and all medium. If we look from the single evaluation index, the first group of data is discrete (maximum data for 80 , the minimum data of 45); a second group of data is evener, obviously the second set of data is better, evaluation of structure is not consistent with the fact. 


\section{Optimization of PQI introduction of weighted geometric average calculation}

The weighted geometric mean can eliminate a set of data in discrete larger data for overall evaluation results, the influence of multiple parameters between cannot compensate each other. To define PQI as follow:

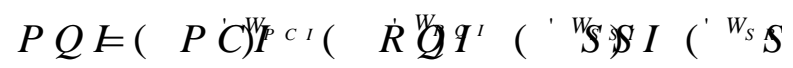

Also, will the data in table 8 PCI, RQI, SSI, SRI is used to calculate the PQI by type (9), the results are shown in table 9.

Table 9 Calculation results of two sections of PQI

\begin{tabular}{|l|c|c|c|c|c|}
\hline $\begin{array}{c}\text { parameter } \\
\text { group }\end{array}$ & PCI $^{\prime}$ & RQI' $^{\prime}$ & SSI' & SRI' & PQI \\
\hline 1 group & 80 & 45 & 78 & 82 & 63.4 \\
\hline 2 group & 68 & 65 & 60 & 71 & 65.8 \\
\hline
\end{tabular}

From table 9 we found that, with the aid of weighted geometric average PQI, two groups of PQI data settlement results have obvious difference, and a second group of data is better than the first set of data, the data reflects the fact that the consistent is obvious; At the same time, we also found that the first group of data of RQI value also significantly influence the outcome of the integrated data PQI, suggesting that can't be mutual compensation between multiple indicators. Through the comparison of calculation result table 7 and table 8 , the application of weighted geometric average more scientific.

\section{Conclusion}

High grade highway asphalt pavement performance evaluation is an important part of modern highway maintenance management. This article begins wtih a single evaluation index of asphalt pavement of four sides by using weighted average method to evaluate the asphalt roadbed comprehensive performance indicator; However, because the weighted average method cannot reflect the overall traffic index (PQI), so we introduced the weighted geometric mean method. It is closer to the actual situation of road, more reasonable than the weighted average method, and therefore more practical.

\section{Reference}

[1] Garey.W.N., P.E.Irick. The pavement-Serviceability Concept Highway Research Board B ulletin 250. National Research Council. Washington, D.C,1960

[2] Lijun Sun etc. Asphalt Pavement Structural Behavior Theory. People's Traffic Press,2005: 39

[3] Paterson W D O. Pavement Behavior and Performance:HIGHLIGHTS-PART 1.Proceedin gs of the 7th International Conference on Asphalt Pavements, Nottingham:ISAP,1992

[4] Yuli Pan. Pavement Panagement System Management System Basic Tutorial[M].Beijing: People's Education Press,2002

[5] Wenxiong Huang. Freeway Asphalt Pavement Performance Evaluation Method Researc h Based On Hybrid Genetic Neural Network [D].Hubei:Wuhan University Of Technology,2 003 
[6] Xianghong, He,Hongli Zhao,Jinfang Gong. Highway Engineering Maintenance And Mana gement[M].Zhengzhou: The Yellow River Water Conservancy Press,2015

[7] The Ministry Of Communications Of the People's Republic Of China. The Freeway M aintenance Quality Evaluation Method[M].Beijing: People's Traffic Press,2003

[8] Baoban Wei. Maukov Decision-making Level In The Application Of The Pavement Man agement System[D].Changsha: Hunan Nniversity,2003 